\title{
Influence of fish oil or folate supplementation on the time course of plasma redox markers during pregnancy
}

\author{
Corinna Franke ${ }^{1}$, Hans Demmelmair ${ }^{1}$, Tamas Decsi ${ }^{2}$, Cristina Campoy ${ }^{3}$, Milagros Cruz ${ }^{3}$, \\ Juan A. Molina-Font ${ }^{3}$, Klaus Mueller ${ }^{4}$ and Berthold Koletzko ${ }^{1 *}$ \\ ${ }^{1}$ Division of Metabolism and Nutrition, Dr. v. Hauner Children's Hospital, Munich, Germany \\ ${ }^{2}$ Department of Pediatrics, University of Pécs, Hungary \\ ${ }^{3}$ Department of Pediatrics, University of Granada, Spain \\ ${ }^{4}$ Department of Pediatrics, University of Frankfurt am Main, Germany
}

(Received 25 November 2008 - Revised 1 December 2009 - Accepted 9 December 2009 - First published online 9 March 2010)

\begin{abstract}
Maternal supplementation with long-chain PUFA, to improve infant neurological development, might cause additional increase of oxidative stress. Pregnant women aged 18-41 years were randomised into one of four supplementation groups. From week 22 on, they received supplements containing either modified fish oil ( $n$ 69), 5-methyl-tetrahydro-folate $(n$ 65), both ( $n$ 64), or placebo ( $n$ 72). Plasma Trolox-equivalent antioxidative capacity (TEAC), concentrations of $\alpha$-tocopherol, retinol, $\beta$-carotene, free thiol groups, uric acid and thiobarbituric acid-reactive substances (TBARS) were determined at weeks 20 and 30 and at delivery. The studied antioxidants showed no significant differences between the four supplementation groups. At week 30 plasma TBARS levels were found to be significantly higher in the fish oil group (0.80 (SEM 0.04) $\mu$ mol/l) than in the folate $(0.67$ (SEM 0.03) $\mu \mathrm{mol} / \mathrm{l} ; P=0.024)$ and control $(0.69$ (SEM 0.04$) \mu \mathrm{mol} / \mathrm{l} ; P=0.01)$ groups. Concentrations of retinol and free thiol groups decreased during pregnancy, whereas uric acid increased and $\beta$-carotene as well as TEAC showed only minor changes. Fish oil supplementation during the second half of pregnancy appears not to decrease antioxidant status. The increased TBARS levels at week 30 may indicate a period of increased oxidative stress in plasma at this time.
\end{abstract}

Pregnancy: DHA: Oxidative stress: Thiobarbituric acid-reactive substances

Oxidative stress occurs as a result of an increase in oxidant generation, a decrease in antioxidant protection, or a failure to repair oxidative damage. Damage to cells results from reactive oxygen species-induced alteration of PUFA in membrane lipids, proteins and DNA. During pregnancy, oxidative stress increases, but there is also an increase of antioxidants and antioxidative enzymes ${ }^{(1,2)}$. Imbalances between oxidants and the antioxidative system may be associated with the onset of pre-eclampsia $^{(3,4)}$ and with an increased risk of miscarriage ${ }^{(1)}$. Furthermore, an inverse correlation between the maternal oxidative stress biomarkers malondialdehyde (for lipid peroxidation) and 8-hydroxydeoxyguanosine (for DNA peroxidation) and neonatal birth weight has been demonstrated ${ }^{(5)}$.

Increased availability of $n-3$ long-chain PUFA, for example, DHA, during the perinatal period has been reported to improve cognitive and visual development of the infant ${ }^{(6-8)}$. The fetus accumulates up to $50 \mathrm{mg}$ DHA per $\mathrm{d}$ in brain and adipose tissue during the last 3 months of gestation ${ }^{(9)}$. Fish oil supplementation in pregnancy was found to slightly prolong mean duration of gestation time and to markedly lower the risk for early preterm delivery ${ }^{(10,11)}$. However, long-chain PUFA are susceptible to peroxidation ${ }^{(12)}$ and additional oxidative stress might be caused by a high dietary intake of $n-3$ fatty acids without adequate antioxidative protection ${ }^{(13)}$.

In women of childbearing age adequate folate supply reduces the incidence of neural tube defects in infants and in the general population. Folate supplementation can reduce plasma concentrations of homocysteine ${ }^{(14)}$. During pregnancy this might improve placental vascularisation and hence maternal-fetal substrate transfer. In line with this hypothesis Böhles et al. showed a negative correlation between maternal plasma homocysteine and DHA-percentage in the erythrocyte membrane phospholipids of their newborns ${ }^{(15)}$. Thus a combined supplementation with folate and $n-3$ long-chain PUFA seems reasonable. As several reactions of homocysteine metabolism (for example, formation of homocysteine) promote the formation of reactive oxygen species, folate supplementation might beneficially influence redox markers ${ }^{(16)}$.

The aim of the present study was to compare oxidative stress and antioxidant levels in pregnant women with and without an $n-3$ long-chain PUFA supplementation, considering a potentially confounding influence of folate supplementation.

Since redox status cannot be adequately assessed from a single analytical parameter, we analysed a set of biomarkers

\footnotetext{
Abbreviations: TBARS, thiobarbituric acid-reactive substances; TEAC, Trolox-equivalent antioxidant capacity; w20, week $20 \pm 1$ of gestation; w30, week $30 \pm 1$ of gestation.

* Corresponding author: Professor Berthold Koletzko, fax +49 895160 3336, email office.koletzko@med.uni-muenchen.de
} 
in the plasma of pregnant women participating in a randomised clinical trial on the effect of fish oil supplementation during the second half of pregnancy on pregnancy outcome $^{(17)}$. Vitamin $\mathrm{E}$ is the major lipid-soluble, peroxidation chain-breaking antioxidant ${ }^{(18)}$. $\beta$-Carotene is an effective scavenger of peroxyl radicals ${ }^{(19)}$ and it is a precursor of retinol, which is of essential importance for growth and development of cells and tissues. Uric acid is a powerful scavenger of singlet oxygen and other radicals ${ }^{(20)}$. Thiol groups, mainly from glutathione, are susceptible to oxidative changes and play an important role in antioxidative reactions ${ }^{(21)}$. Because there are more antioxidants and interactions in the aqueous phase of plasma, we measured Trolox-equivalent antioxidant capacity (TEAC) in plasma as an integrative parameter. In addition, the plasma concentration of thiobarbituric acidreactive substances (TBARS) was determined as a marker of lipid peroxidation.

\section{Subjects and methods}

\section{Subjects and enrolment}

The present study was conducted according to the guidelines laid down in the Declaration of Helsinki and all procedures involving human subjects were approved by the local Ethical Committees of the participating centres. From November 2001 to March 2003, pregnant women were recruited in Granada (Spain), Pécs (Hungary) and Munich (Germany). Women attending antenatal care clinics for ultrasound examinations between week 12 and week 20 of gestation were approached by study personnel, informed about the aims and nature of the study and invited to participate. Subject information includes an oral explanation by the physician and a written informed consent which was given to the subject. The criteria for inclusion were: age at study entry of 18-41 years, uncomplicated singleton pregnancy and weight at study entry of $50-95 \mathrm{~kg}$. Women taking folate supplements after week 16 of gestation or fish oil supplements since they became pregnant were excluded from the study. Furthermore, for this analysis all women who smoked during pregnancy were excluded because smoking may enhance oxidative stress. Details of the study protocol and execution have been previously reported $^{(17)}$.

Participants who agreed to participate were randomised without stratification into one of four dietary supplementation groups separately at each centre. To ensure that the different supplementation groups are nearly equally represented in each centre, randomisation was performed in blocks of twenty numbers. For this purpose twenty envelopes containing cards with one of the four numbers according to the supplementation groups were prepared and put into a closed box. By drawing envelopes, supplementation group numbers were assigned to the subject identity number. This procedure was performed identically for each study centre. After allocation to the dietary group, women were provided correspondingly with ninety sachets of $15 \mathrm{~g}$, of which they had to consume one per $d$. At the second investigation date in week $30 \pm 1($ w30) of gestation a further batch of ninety sachets was provided for the rest of pregnancy.

Thus, from week 22 of gestation onwards participants received milk-based supplements containing either modified
Table 1. Nutrition, mineral and vitamin content of the supplements according to manufacturer's analysis (nutrient supply per sachet of $15 \mathrm{~g}$ )

\begin{tabular}{|c|c|c|c|c|}
\hline Group... & Fish oil & Folate & Fish oil + folate & Control \\
\hline $\mathrm{DHA}(\mathrm{mg})$ & 500 & - & 500 & - \\
\hline EPA (mg) & 150 & & 150 & \\
\hline 5-MTHF $(\mu \mathrm{g})$ & - & 400 & 400 & - \\
\hline \multicolumn{5}{|l|}{ Energy } \\
\hline $\mathrm{kJ}$ & 297 & 293 & 297 & 293 \\
\hline kcal & 71 & 70 & 71 & 70 \\
\hline Protein $(\mathrm{g})$ & $2 \cdot 5$ & $2 \cdot 9$ & $2 \cdot 5$ & $2 \cdot 9$ \\
\hline Fat (g) & $3 \cdot 1$ & 2.9 & $3 \cdot 1$ & $2 \cdot 9$ \\
\hline Carbohydrates (g) & $8 \cdot 2$ & $8 \cdot 0$ & $8 \cdot 2$ & $8 \cdot 0$ \\
\hline Vitamin $A(\mu \mathrm{g})$ & 330 & 330 & 330 & 330 \\
\hline Vitamin D $(\mu \mathrm{g})$ & 1.5 & 1.5 & 1.5 & 1.5 \\
\hline Vitamin E (mg) & 3 & 3 & 3 & 3 \\
\hline Thiamin (mg) & 0.36 & 0.36 & 0.36 & 0.36 \\
\hline Riboflavin (mg) & 1.5 & 1.5 & 1.5 & 1.5 \\
\hline Niacin $(\mathrm{mg})$ & 4.5 & 4.5 & 4.5 & 4.5 \\
\hline Vitamin $B_{6}(\mathrm{mg})$ & 1.9 & 1.9 & 1.9 & 1.9 \\
\hline Vitamin $B_{12}(\mu \mathrm{g})$ & 3.5 & 3.5 & 3.5 & 3.5 \\
\hline Vitamin C (mg) & 270 & 270 & 270 & 270 \\
\hline $\mathrm{Ca}(\mathrm{mg})$ & 300 & 300 & 300 & 300 \\
\hline$P(\mathrm{mg})$ & 240 & 240 & 240 & 240 \\
\hline $\mathrm{Mg}(\mathrm{mg})$ & 93 & 93 & 93 & 93 \\
\hline $\mathrm{Zn}(\mathrm{mg})$ & 3 & 3 & 3 & 3 \\
\hline $\mathrm{I}(\mu \mathrm{g})$ & 66 & 66 & 66 & 66 \\
\hline
\end{tabular}

5-MTHF, 5-methyl-tetrahydro-folate.

fish oil providing $500 \mathrm{mg}$ DHA and $150 \mathrm{mg}$ EPA per d (fish oil group), or $400 \mu \mathrm{g}$ 5-methyl-tetrahydro-folate (MTHF) per d (folate group), both in combination (fish oil + MTHF; fish oil + folate group) or placebo (control group). All supplements provided the estimated additional requirements for minerals and vitamins during the second half of pregnancy (Table 1).

Non-fasting maternal venous blood samples for the laboratory analyses were collected at week $20 \pm 1$ (w20) of gestation, before supplementation started, at w30 and at the time of delivery using EDTA as anticoagulant. The plasma samples were stored at $-80^{\circ} \mathrm{C}$ until assayed. At the same time points a well-trained physician performed standardised interviews with the woman to assess data about socioeconomic status, obstetrical history, intercurrent diseases and maternal smoking habits. Additionally, maternal height, weight and blood pressure were measured. At w20 and w30 participating women completed a FFQ to assess the DHA and folate intake with their habitual diet. Details of the nutritional evaluation have previously been reported ${ }^{(22)}$.

\section{Analytical procedures}

TBARS, TEAC, free thiol-groups, total protein and uric acid concentrations from all samples of each woman were analysed during one and the same day.

TBARS concentrations were determined by reaction with 2-thiobarbituric acid, based on the method of Knight et al. ${ }^{(23)}$. Ortho-phosphoric acid $(500 \mu \mathrm{l} ; 0.44 \mathrm{M}), 100 \mu \mathrm{l}$ plasma and $200 \mu \mathrm{l}$ 2-thiobarbituric acid solution $(60 \mathrm{mg}$ per $10 \mathrm{ml}$ water) were pipetted into reaction vials. The mixture was heated in a water-bath for $1 \mathrm{~h}$ to $100^{\circ} \mathrm{C}$. After cooling, a $100 \mu \mathrm{l}$ sample was added to a $100 \mu \mathrm{l}$ methanol$\mathrm{NaOH}$ mixture $(0.45 \mathrm{ml} 1 \mathrm{M}-\mathrm{NaOH}$ per $4.55 \mathrm{ml}$ methanol). 
After centrifugation a $50 \mu \mathrm{l}$ portion of the supernatant fraction was used for HPLC with fluorescence detection (excitation, $550 \mathrm{~nm}$; emission, $532 \mathrm{~nm}$ ) for the measurement of TBARS ${ }^{(23)}$. External calibration with 1,1,3,3-tetraethoxypropane was used to quantify TBARS in the plasma samples. Intra- and interassay CV were 2.6 and $8.8 \%$, respectively.

Plasma $\alpha$-tocopherol, retinol and $\beta$-carotene concentrations were analysed at the Department of Paediatrics, University of Frankfurt am Main (Germany) by an established HPLC method with UV detection after extraction of lipids into hexane ${ }^{(24)}$. An external standard was applied for quantification. Plasma $\alpha$-tocopherol is given as concentration and in relation to plasma lipids ( $\alpha$-tocopherol:cholesterol + TAG ratio).

Free thiol-groups were determined using Ellman's reagent $\left(5,5^{\prime} \text {-dithio-bis 2-nitrobenzoic acid }\right)^{(25)}$. Micro-plate wells were filled with $165 \mu \mathrm{l}$ water, $60 \mu \mathrm{l}$ phosphate-saline buffer $(0 \cdot 1 \mathrm{M}), 15 \mu \mathrm{l}$ plasma or standard and $60 \mu \mathrm{l}$ Ellman's reagent $\left(10 \mathrm{~mm}\right.$ in $0 \cdot 15 \mathrm{M}-\mathrm{NaCl}$ and $0.1 \mathrm{M}-\mathrm{Na}_{3} \mathrm{PO}_{4}$ ). Blanks were measured with each plasma sample, containing distilled water instead of Ellman's reagent, and one blank containing pure water instead of plasma. The reaction was allowed to proceed during incubation at room temperature for at least $15 \mathrm{~min}$ on a shaker plate, before absorption was measured at $405 \mathrm{~nm}$ (photometer anthos ht III; Labtec Instruments, Wals, Austria). A five-point calibration curve was prepared daily using fresh cysteine solution. Intra- and inter-assay $\mathrm{CV}$ averaged 6.6 and $8.9 \%$, respectively.

The measurement of TEAC is based on the inhibition of the formation of 2,2'-azino-bis(3-ethylbenzothiazoline6-sulphonic acid) $\left(\mathrm{ABTS}^{+}\right)$radical cations by antioxidants ${ }^{(26)}$. PBS buffer (506 $\mu \mathrm{l} ; 5 \mathrm{~mm}$; pH 7.4), $36 \mu$ l myoglobine (70 $\mu \mathrm{M})$, $300 \mu 1$ 2,2'-azino-bis(3-ethylbenzothiazoline-6-sulphonic acid) $(500 \mu \mathrm{M})$ and $8.4 \mu \mathrm{l}$ plasma were combined. The mixture was incubated for $3 \mathrm{~min}$ at $30^{\circ} \mathrm{C}$. The reaction was started by the addition of $150 \mu \mathrm{l} \mathrm{H}_{2} \mathrm{O}_{2}(450 \mu \mathrm{M})$, which was prepared fresh every day, and after $3 \mathrm{~min}$ absorbance at $734 \mathrm{~nm}$ was read. Trolox (6-hydroxy-2,5,7,8-tetramethylchroman-2-carboxylic acid diluted in $2.5 \mathrm{~mm}$-PBS) was used for calibration. The intra- and inter-assay $\mathrm{CV}$ averaged 1.1 and $4.7 \%$, respectively.

Cholesterol, TAG, total protein and uric acid were analysed with an automatic Hitachi analysis system (Fa. Boehringer, Mannheim, Germany), using enzymic assays for cholesterol, TAG, uric acid and a colour test for total protein, respectively.

\section{Statistical analysis}

Data were analysed with SPSS for Windows 12.0 (SPSS Inc., Chicago, IL, USA). Normal distribution was examined using the Kolmogorow-Smirnov test (with Lilliefors correction). One-way ANOVA with post hoc Bonferroni correction was used to evaluate differences between supplementation groups for normally distributed data. In the case of non-normal distribution the Mann-Whitney $U$ test was applied. Statistical significance was assumed at $P<0 \cdot 05$. Differences over time were evaluated using a general linear model. Correlations between parameters were estimated by computing Pearson's correlation coefficient in the case of normally distributed values and the Spearman $\rho$ correlation coefficient in the case of other distributions, respectively.

\section{Results}

\section{Study participants}

From the 311 women enrolled into the study, forty-one women were excluded from the analyses because they did not complete the study. Reasons for dropping out were noncompliance ( $n$ 2), relocation ( $n$ 1), aversion to or bad taste of the supplement ( $n 9)$, and the loss of contact $(n 2)$ ). For the remaining cases, a special reason for drop out could not be identified. From 270 study participants who completed the study ${ }^{(17)}$, samples were available for sixty-five women recruited in Munich, 113 in Granada and fifty-four in Pècs, respectively. Allocation of these women to the different intervention groups was: fish oil group ( $n$ 69), folate group ( $n$ 65), control group ( $n$ 72) and fish oil + folate group ( $n$ 64). Age and BMI were not significantly different between the four supplementation groups at study entry (Table 2). The four supplementation groups differed at none of the time points in BMI and weight gain during pregnancy. The whole study population showed an average weight gain of 5.8 (SEM $3.8) \mathrm{kg}$ from $\mathrm{w} 20$ to $\mathrm{w} 30$ and 4.2 (SEM 3.5 ) $\mathrm{kg}$ from $\mathrm{w} 30$ until the end of pregnancy. Weight development was not different between the groups.

\section{Effects of fish oil and folate supplementation on maternal plasma}

Plasma cholesterol levels were significantly different over time of pregnancy in the whole study population (w20, 5.72

Table 2. Characteristics of the participants in the four supplementation groups*

(Median values and interquartile ranges (IQR))

\begin{tabular}{|c|c|c|c|c|c|c|c|c|c|c|c|}
\hline \multirow[t]{2}{*}{ Group... } & \multicolumn{2}{|c|}{ Fish oil } & \multicolumn{2}{|c|}{ Folate } & \multicolumn{2}{|c|}{ Control } & \multicolumn{2}{|c|}{ Fish oil + folate } & \multicolumn{2}{|c|}{$\begin{array}{l}\text { Total study } \\
\text { population }\end{array}$} & \multirow[b]{2}{*}{$P$} \\
\hline & Median & IQR & Median & IQR & Median & IQR & Median & IQR & Median & IQR & \\
\hline $\begin{array}{l}\text { Age at study entry } \\
\text { (years) }\end{array}$ & $31 \cdot 2$ & $27 \cdot 4-34 \cdot 0$ & 31.9 & $26 \cdot 1-35 \cdot 2$ & $31 \cdot 0$ & $28 \cdot 4-34 \cdot 8$ & 31.9 & $28 \cdot 0-35 \cdot 2$ & $31 \cdot 3$ & $27 \cdot 6-34 \cdot 8$ & 0.62 \\
\hline \multicolumn{12}{|l|}{$\mathrm{BMI}\left(\mathrm{kg} / \mathrm{m}^{2}\right)$} \\
\hline w20 & $25 \cdot 2$ & $22 \cdot 8-28 \cdot 2$ & $24 \cdot 3$ & $22 \cdot 2-27 \cdot 3$ & $24 \cdot 2$ & $23 \cdot 0-26 \cdot 6$ & $24 \cdot 5$ & $23 \cdot 1-27 \cdot 2$ & $24 \cdot 6$ & $22 \cdot 8-27 \cdot 4$ & 0.42 \\
\hline w30 & $27 \cdot 7$ & $25 \cdot 0-31 \cdot 6$ & $26 \cdot 2$ & $24 \cdot 2-28 \cdot 3$ & $26 \cdot 4$ & $25 \cdot 0-29 \cdot 1$ & $26 \cdot 2$ & $24 \cdot 6-29 \cdot 1$ & $26 \cdot 5$ & $24 \cdot 7-29 \cdot 5$ & 0.37 \\
\hline Delivery & $29 \cdot 1$ & $26 \cdot 4-33 \cdot 0$ & $27 \cdot 5$ & $25 \cdot 3-30 \cdot 3$ & 28.4 & $26 \cdot 6-31 \cdot 1$ & $28 \cdot 2$ & $26 \cdot 4-31 \cdot 2$ & $28 \cdot 4$ & $26 \cdot 4-31 \cdot 3$ & 0.27 \\
\hline
\end{tabular}

w20, Week $20 \pm 1$ of gestation; w30, week $30 \pm 1$ of gestation.

${ }^{*}$ Group-specific statistical differences were assessed by ANOVA (with Bonferroni correction) and the Kruskal-Wallis test. 
(SEM 0.06); w30, 6.64 (SEM 0.08); delivery, 6.24 (SEM $0.09) \mathrm{mmol} / \mathrm{l} ; P<0.001$ ). In all supplementation groups the highest plasma mean cholesterol value was found at w30 and the lowest at baseline, before supplementation started (Table 3). A significant difference $(P=0.003)$ at w30 was found between women supplemented with fish oil (fish oil and combined groups: 6.78 (SEM 0.10) mmol/l) and nonsupplemented women (folate and control groups: 6.18 (SEM $0 \cdot 17) \mathrm{mmol} / \mathrm{l}$ ). There were no other significant differences between the supplementation groups. Plasma TAG values increased significantly with advancing pregnancy (w20, 1.72 (SEM 0.04); w30, 2.26 (SEM 0.05); delivery, 2.30 (SEM $0.06) \mathrm{mmol} / \mathrm{l} ; P<0.01)$ without significant group differences at the different time points $(P=0 \cdot 30$; Table 3$)$.

Supplementation did not affect plasma total protein levels (general linear model: $P=0.723$ ). But all supplementation groups showed time-dependent changes. With exception of the combined group $(P=0.04)$, total plasma protein levels were similar at $\mathrm{w} 20$ and $\mathrm{w} 30$ and decreased towards delivery in all groups $(P<0 \cdot 001$; Table 3). Between all time points we found significant correlations for plasma total protein (w20-w30, $r$ 0.54; w30-delivery, $r 0.34 ; P<0.001$ ).

Plasma TBARS concentrations at w20 showed no significant differences between the supplementation groups. At w30 we found a significant difference between the DHA group and the folate group $(P=0.047$; Fig. 1$)$. In all four groups, plasma TBARS increased significantly from w30 until the end of pregnancy. Subjects with $n-3$ long-chain PUFA in their supplement, with or without folate, had higher plasma TBARS concentrations at w30 $(P=0.042)$ and at delivery than non- $n-3$ long-chain PUFA-supplemented groups ( $P=0.030$; Fig. 2). Plasma TBARS level showed no differences from $\mathrm{w} 20$ to $\mathrm{w} 30$ in groups with the fish oil supplement, but decreased significantly without the fish oil supplement $(P=0.001$; Fig. 2). We found no significant effect of the study supplement on the plasma TBARS levels (general linear model: $P=0 \cdot 305$ ). Plasma TBARS correlations between the different time points in the whole study group (w20-w30, $r 0.35, P<0.001$; w30-delivery, $r 0 \cdot 21, P=0.03$ ) and in women with fish oil supplementation (fish oil and combined groups) were statistically significant (w20-w30, $r 0 \cdot 22$, $P=0.021$; w30-delivery, $r 0.28, P=0.006$ ). However, there was only a significant correlation in the subjects not supplemented with fish oil (folate and control groups) between

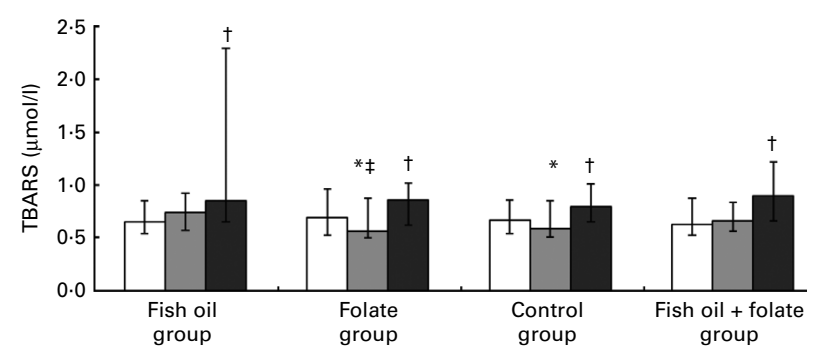

Fig. 1. Maternal thiobarbituric acid-reactive substances (TBARS) plasma levels in the different supplementation groups over time: week $20 \pm 1$ of gestation (w20; $\square$ ); week $30 \pm 1$ of gestation (w30; $\square$ ); delivery (ם). Values are medians, with interquartile ranges represented by vertical bars. * Median value was significantly different from that at w20 $(P<0.05)$. †Median value was significantly different from that at w30 $(P<0.05)$. $¥$ Median value was significantly different from that of the fish oil group at w30 $(P<0.05)$. 

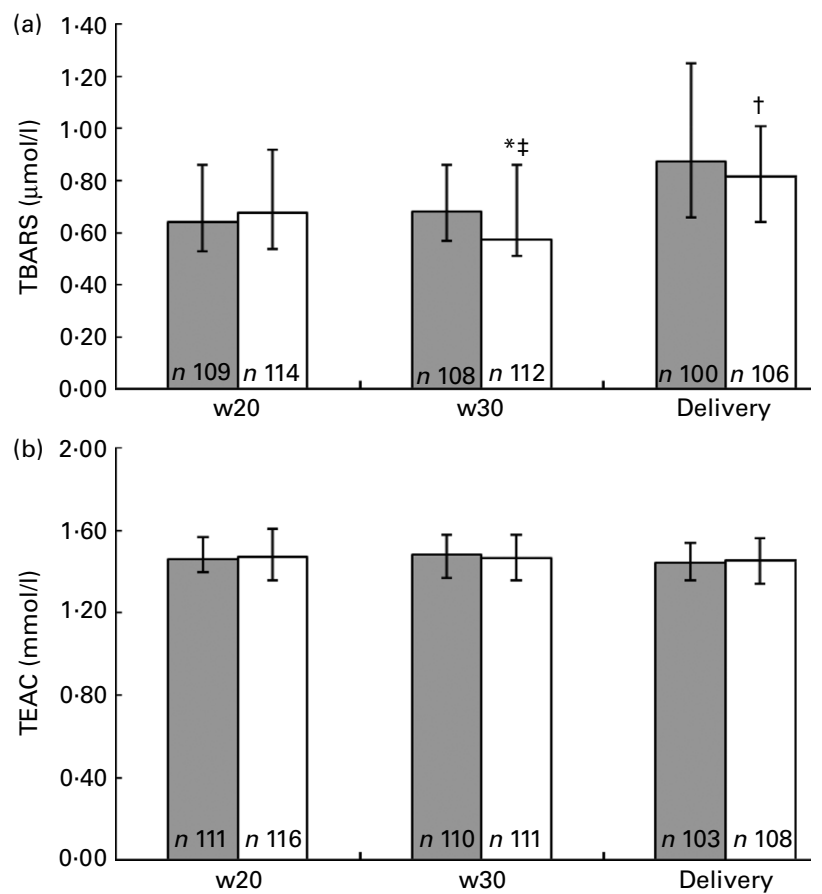

Fig. 2. Plasma thiobarbituric acid-reactive substances (TBARS) (a) and Trolox-equivalent antioxidant capacity (TEAC) (b) values in women with ( $\square$ ) and without $(\square)$ fish oil in their supplementation over time: week $20 \pm 1$ of gestation (w20); week $30 \pm 1$ of gestation (w30); delivery. Values are medians, with interquartile ranges represented by vertical bars. * Median value was significantly different from that of the women receiving the fish oil supplementation at the same time point $(P=0.042)$. † Median value was significantly different from that of the women receiving the fish oil supplementation at the same time point $(P=0.030)$. $¥$ Median value was significantly different from that of the women not receiving the fish oil supplementation at w20 $(P=0.001)$.

w20 and w30 (w20-w30, $r$ 0.37, $P<0.001$; w30-delivery, $r$ 0.05; NS). Only at w30 were there significant negative correlations between TBARS and the plasma $\alpha$-tocopherol concentration $(r-0.21 ; P=0.002)$ and the $\alpha$-tocopherol:lipids ratio $(r-0 \cdot 24 ; P<0 \cdot 001)$.

The concentration of plasma $\alpha$-tocopherol was related to total lipids (cholesterol + TAG) and rose between w20 and w30 significantly in all four supplementation groups $(P<0.001)$. From w30 until the end of pregnancy the plasma $\alpha$-tocopherol concentrations showed no differences in all groups (Table 4). Supplementation had no effect on the plasma $\alpha$-tocopherol:lipid ratio; during the whole intervention time no differences were found between the supplementation groups. Significant intra-individual correlations of the $\alpha$-tocopherol:lipid ratio in the study population were found between w20 and w30 $(r 0.27 ; P<0.001)$ as well as w30 and delivery $(r 0.27 ; P<0.001)$. Correlations between these time points were also significant for $\alpha$-tocopherol concentrations (w20-w30, $r$ 0.45, $P<0.001$; w30-delivery, $r 0.40, P<0.001)$.

Plasma TEAC was not affected by supplementation at any time point (Table 4). There were no significant changes over time and no differences between fish oil-supplemented and non-fish oil-supplemented women (Fig. 2). Significant intraindividual correlations of TEAC at all time points were found in the total population (w20-w30, $r$ 0.82, $P<0 \cdot 001$; w30-delivery, $r \quad 0.70, \quad P<0 \cdot 001)$. Plasma TEAC levels correlated significantly with $\beta$-carotene levels at w20 ( $r$ 0.18; $P=0.006)$ and w30 $(r 0 \cdot 14 ; P=0 \cdot 034)$. Other correlations were obtained between TEAC and retinol (w20, $r$ 0.32, $P<0 \cdot 001$; w30, $r$ 0.28, $P<0.001$; delivery, $r 0.21, P=0.002)$, TEAC and $\alpha$-tocopherol (w30, $r$ 0.29, $P<0.001$; delivery, $r$ 0.45; $P<0.001)$ as well as between TEAC and total protein (w20, $r 0 \cdot 17, P=0.009$; delivery, $r 0.36 ; P<0 \cdot 001)$. No correlations were found between TEAC and uric acid and the free thiol groups, respectively.

Maternal retinol levels decreased in the whole study population with increasing duration of pregnancy $(P<0.001$; w20, 2.74 (SEM 0.08) $\mu \mathrm{mol} / \mathrm{l}$; w30, 2.18 (SEM 0.07) $\mu \mathrm{mol} / \mathrm{l}$; delivery, 1.99 (SEM 0.07) $\mu \mathrm{mol} / \mathrm{l}$ ). Significant changes between w20 and w30 were found in all four groups (Table 4) and a significant change between w30 and delivery was found in the fish oil group $(P=0.008)$. Splitting women into subjects with (fish oil and combined groups) and without fish oil supplementation (folate + control groups) resulted in significant differences between w20 and w30 in both groups (with fish oil: $P=0.002$, w20, 2.70 (SEM 0.11) $\mu \mathrm{mol} / \mathrm{l}$; w30, 2.2 (SEM 0.10) $\mu \mathrm{mol} / \mathrm{l}$; without fish oil: $P<0.001$, w20, 2.72 (SEM 0.11) $\mu \mathrm{mol} / \mathrm{l}$; w30, 1.99 (SEM 0.09) $\mu \mathrm{mol} / \mathrm{l}$ ) and between w30 and delivery only in fish oil-supplemented women $(P=0.002$; delivery, 1.86 (SEM 0.12$) \mu \mathrm{mol} / \mathrm{l})$. Between supplementation groups we found no significant differences at any of the time points. Intra-individual correlations of the plasma retinol levels were significant between all time points (w20-w30, $r$ 0.40, $P<0.001$; w30-delivery, $r 0.23 ; P<0.001)$.

The plasma $\beta$-carotene levels showed different developments in women with and without fish oil supplementation. Both the folate and control groups showed a significant decrease between $\mathrm{w} 20$ and $\mathrm{w} 30(P=0.014 ; P=0.002)$, as well as all subjects without fish oil supplementation taken together (control and folate groups: w20, 0.52 (SEM 0.04) $\mu \mathrm{mol} / \mathrm{l}$; w30, 0.41 (SEM 0.04) $\mu \mathrm{mol} / \mathrm{l} ; P<0.001$ ). In all groups, the lowest plasma $\beta$-carotene concentration was found at the end of pregnancy. There were no significant differences between the four supplementation groups at any of the time points. Comparing women with fish oil (fish oil and combined groups) and those without fish oil supplementation (control and folate groups), we found a significant difference at w30 $(P=0 \cdot 03)$ and delivery $(P=0 \cdot 04)$. In both cases, women with fish oil supplementation had higher $\beta$-carotene concentrations (with fish oil: w30, 0.51 (SEM 0.04) $\mu \mathrm{mol} / \mathrm{l}$; delivery, 0.42 (SEM 0.03) $\mu \mathrm{mol} / \mathrm{l}$; without fish oil: w30, 0.42 (SEM 0.04) $\mu \mathrm{mol} / \mathrm{l}$; delivery, 0.38 (SEM 0.04) $\mu \mathrm{mol} / \mathrm{l})$. Correlations between the time points were significant (w20-w30, $r$ 0.60; w30-delivery, $r 0.75 ; P<0.001$ ) in the whole study population.

Plasma free thiol groups decreased until the end of pregnancy, but no differences were found between the four supplementation groups, as well as between fish oilsupplemented (fish oil and combined groups) and non-fish oil-supplemented (control and folate groups) subjects. A significant decrease between w30 and delivery was found in all four groups (Table 4). Correlations were significant between all time points (w20-w30, $r$ 0.49; w30-delivery, $r 0.45$; each $P<0.001$ ). At all time points we found significant correlations between the concentrations of total protein and the free thiol groups (w20, $r$ 0.22, $P=0.001$; w30, $r$ 0.34; 
Fish oil and redox status in pregnancy

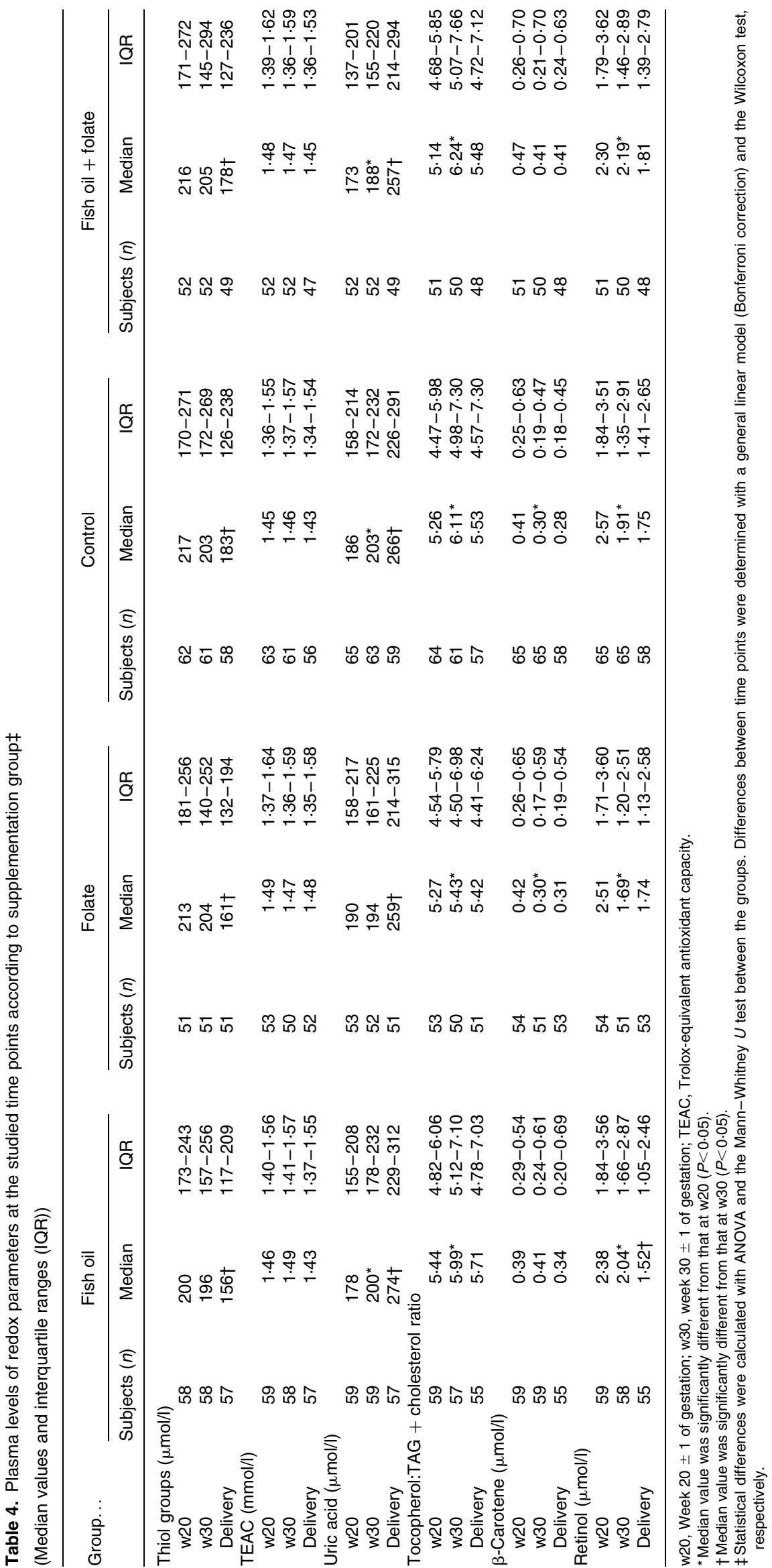


delivery, $r 0 \cdot 44, P<0 \cdot 001)$. The ratio of thiol groups per total protein did not differ between the supplementation groups.

In the whole study population, plasma uric acid level showed a slight increase between w20 and w30 (510 (SEM 14) to $551(\mathrm{SEM} 8) \mu \mathrm{mol} / \mathrm{l} ; P<0.001)$ and a stronger increase towards the end of pregnancy (739 (SEM 13) $\mu \mathrm{mol} / \mathrm{l}$; $P<0 \cdot 001)$. There was no significant effect of the supplementation on maternal uric acid level during intervention time (general linear model: $P=0 \cdot 60$ ). Except the folate group $(P=0 \cdot 07)$, all groups showed a significant increase between w20 and w30 $(P \leq 0 \cdot 001)$. Between w30 and delivery, all four groups showed a significant increase $(P<0 \cdot 001)$. Significant correlations with $P<0.001$ were found between w20 and w30 $(r$ 0.65) as well as w30 and delivery $(r 0.60)$ in the total study population.

\section{Dietary intake of DHA}

The analysis of the FFQ showed no significantly different DHA intake with habitual diet between the supplementation groups at $\mathrm{w} 20$ and $\mathrm{w} 30$. DHA intake in the study population was $30.1 \mathrm{mg}$ per $1000 \mathrm{~kJ}(126 \mathrm{mg}$ per $1000 \mathrm{kcal})$ at w20 and $29.4 \mathrm{mg}$ per $1000 \mathrm{~kJ}(123 \mathrm{mg}$ per $1000 \mathrm{kcal})$ at w30 on average $^{(22)}$. We found no significant difference regarding the dietary intakes of folate between the four supplementation groups at w20 nor at w30. The study population showed a folate intake of about $27.7 \mu \mathrm{g} / 1000 \mathrm{~kJ}(116 \mu \mathrm{g} / 1000 \mathrm{kcal})$ at both time points with no significant difference between the groups and change with time.

\section{Discussion}

The present study shows a significant increase of plasma TBARS during the second half of pregnancy, independently from supplement allocation. An increase of lipid peroxidation was previously reported with progression of pregnancy, and thus with increasing age of the placenta ${ }^{(27)}$. While measures of peroxidation are generally higher in pregnant women than in non-pregnant controls, results on the evolution of plasma markers of peroxidation during pregnancy are quite variable $^{(28)}$. The significant increase of TBARS in our subjects is in line with the reported increase of lipid hydroperoxides between first and third trimester ${ }^{(29)}$, while a significant increase of plasma malondialdehyde concentration with the course of pregnancy was not observed by Patrick et al. in American women ${ }^{(30)}$. A reason for these divergent results might be that the TBARS test is non-specific for malondialdehyde $^{(31)}$. The mid-pregnancy malondialdehyde concentrations were clearly lower in the women studied by Patrick et al. ${ }^{(30)}$ $(0.38 \mu \mathrm{mol} / \mathrm{l}$ in white and $0.50 \mu \mathrm{mol} / 1$ in black women $)$ than the TBARS concentrations in the European women in the present study $(0.74 \mu \mathrm{mol} / \mathrm{l})$. Thus antioxidative capacity might have been exhausted earlier in our women. An association between lipid peroxidation products and lipid-soluble antioxidants is reflected in the negative correlations between TBARS and $\alpha$-tocopherol in the whole study population at w30 $(r-0 \cdot 21 ; P=0 \cdot 002)$. Fish oil supplementation induced both significantly higher plasma phospholipid DHA and EPA percentages ${ }^{(17)}$ at $w 30$ and at delivery, while plasma TBARS concentrations were only at w30 significantly increased in the fish oil-supplemented group. This might indicate that the antioxidant system was brought to its limits around w30, but adapted later on or at delivery other factors are the determinants of redox status.

Plasma concentrations of $\alpha$-tocopherol and the $\alpha$-tocopherol: lipid ratio increased after $\mathrm{w} 20$, which reflects the additional intake of $\alpha$-tocopherol with the study supplements. While a negative correlation between percentage of total PUFA and vitamin $\mathrm{E}$ has been reported in pregnant Italian women ${ }^{(32)}$, we did not find lower $\alpha$-tocopherol concentrations in the fish oil-supplemented women. The reason seems to be the different amounts of vitamin $\mathrm{E}$ intake. None of the studied Italian women took nutritional supplements containing lipid-soluble vitamins $^{(32)}$. The additional vitamin $\mathrm{E}$ intake with the Nutraceuticals for a Healthier Life (NUHEAL) study supplement might have provided $\alpha$-tocopherol in an amount much higher than the minimal requirement for radical scavenging.

Plasma protection against free radical injury is offered by a wide range of antioxidants with synergistic action. Measurement of all individual antioxidants is not possible; thus we applied the integrative TEAC assay to estimate plasma antioxidative capacity. We did not find significantly lower plasma TEAC in fish oil-supplemented compared with non-supplemented women. In both groups TEAC tended to decrease towards the end of the intervention period. Comparing measured TEAC concentration with antioxidants measured in plasma, we found significant correlations to retinol, $\beta$-carotene and total protein levels, but no correlation to uric acid. TEAC was not affected by the progression of pregnancy and the significant changes in uric acid concentration over time were not reflected. Plasma albumin and uric acid are the major determinants of TEAC, but correlations to specific antioxidant concentrations are difficult to establish and depend on the applied radical-generating substrate and reaction time ${ }^{(33-35)}$.

The decrease of plasma retinol concentration during pregnancy is in agreement with the results of Bruinse et al. ${ }^{(36)}$ and Cikot et al. ${ }^{(37)}$. Possible reasons for a decrease could be the increasing plasma volume during pregnancy, a decrease in retinol-binding proteins or increased tissue retention. The decreased plasma retinol concentration during advanced pregnancy might also reflect enhanced fetal utilisation ${ }^{(32,38)}$.

Significant differences in plasma $\beta$-carotene concentrations were found between fish oil-supplemented and nonsupplemented subjects. In contrast to a short-term n-3 longchain PUFA supplementation study ${ }^{(39)}$, we found higher values of plasma $\beta$-carotene at w30 and at the time of delivery in fish oil-supplemented women. All groups showed the lowest concentrations at the time of delivery, which might be an indication for a higher level of oxidative stress towards the end of gestation as well as the increased maternal blood volume. Several other factors known to influence $\beta$-carotene concentration, such as age, sex, smoking status and residence location, could be excluded as they were not different between the groups $(P>0.05)^{(40)}$. Thus, the reason for the higher $\beta$-carotene concentrations in the fish oil-supplemented women remains unclear.

Uric acid plasma concentration increased significantly throughout pregnancy, irrespective of type of supplementation. A similar increase has been reported in other studies and has been interpreted as reflecting a xanthine-xanthine oxidase pathway stimulation ${ }^{(41,42)}$. Uric acid may act as an 
antioxidant, but there is also evidence that it has pro-oxidative effects $^{(43-45)}$. Thus, increased levels of uric acid indicate oxidative stress, but it is unclear whether it induces oxidative stress or reflects antioxidant activity. In pregnancy elevated uric acid levels have been associated with increased rates of complications such as pre-eclampsia ${ }^{(42)}$. In non-smoking pregnant women, uric acid levels of 197 (SEM 15) $\mu \mathrm{mol} / \mathrm{l}$ (33.1 (SEM 2.5) mg/l) in weeks 16-24 and 194 (SEM 9) $\mu \mathrm{mol} / \mathrm{l}$ (32.6 (SEM 1.5) mg/l) in weeks 24-34 have been reported $^{(46)}$, which is similar to our findings. In contrast, results in smoking pregnant women $(202 \mu \mathrm{mol} / \mathrm{l}(33.9 \mathrm{mg} / \mathrm{l})$; $214 \mu \mathrm{mol} / \mathrm{l}(35.9 \mathrm{mg} / \mathrm{l}))^{(46)}$ tended to be higher than the plasma uric acid in our $n$-3-supplemented women (w20, $179 \mu \mathrm{mol} / \mathrm{l}(30 \mathrm{mg} / \mathrm{l})$; w30, $196 \mu \mathrm{mol} / \mathrm{l}(33 \mathrm{mg} / \mathrm{l}))$. Thus, it appears that the increase with time found in the present study is not related to the $n-3$ supplementation, but rather with falling renal clearance towards the end of pregnancy ${ }^{(46)}$.

Plasma thiol groups showed a decrease in all subjects during the intervention time. The present results confirm the results of previews studies ${ }^{(47,48)}$. The decrease in thiol groups and in total protein levels during pregnancy may reflect the increasing maternal plasma volume and physiological functions of the thiol groups in fetal metabolism, but increases of oxidative stress with pregnancy duration has also been proposed as an explanation ${ }^{(47,49,50)}$. Our data show a similar decrease in all supplementation groups, which was on average $20 \%$ from baseline to delivery. Thus, if an $n-3$ long-chain PUFA supplementation induced oxidative stress, it was too small to influence plasma thiol concentration.

We conclude that the recommended supply of $n-3$ longchain PUFA in pregnancy ${ }^{(51,52)}$, here providing a daily supply of $500 \mathrm{mg}$ DHA and $150 \mathrm{~g}$ EPA, did not affect watersoluble and lipid-soluble antioxidants. Higher TBARS concentrations in the fish oil group were not associated with a depletion of plasma antioxidants, and the group difference was clearly smaller than the increase with pregnancy duration. Independent of the inclusion of folate the applied dosage of $n$-3 long-chain PUFA supplementation seems to be without adverse effects on antioxidative defence in pregnant women.

\section{Acknowledgements}

The authors thank all participating women for their collaboration and all colleagues in the study centres for their support. The present study was financially supported by the Commission of the European Communities within the 5th Framework Programme NUHEAL, CLK1-CT-1999-00888, within the 6th Framework Programmes EARNEST, FoodCT-2005-007036, and EURRECA, FP6-036196-2, and within the 7th Framework Programme NUTRIMENTHE, FP7-212652. This paper does not necessarily reflect the views of the Commission and in no way anticipates the future policy in this area. B. K. is the recipient of a Freedom to Discover Award of the Bristol Myers Squibb Foundation, New York, NY, USA.

All authors have made substantive contributions to the study, and endorse the data and conclusions. The authors contributed as follows: B. K., C. C. and T. D. designed and supervised the study. C. F., K. M., H. D., M. C. and J. A. M.-F. participated in data collection and/or laboratory analyses. C. F. did the statistical analysis and wrote the first draft of the manuscript. B. K., H. D., C. C. and T. D. revised the manuscript and contributed to the final version of the manuscript.

All authors certify that there is no actual or potential conflict of interest in relation to this article.

\section{References}

1. Jenkins C, Wilson R, Roberts J, et al. (2000) Antioxidants: their role in pregnancy and miscarriage. Antioxid Redox Signal 2 , 623-628.

2. Sugino N, Takiguchi S, Kashida S, et al. (2000) Superoxide dismutase expression in the human corpus luteum during the menstrual cycle and in early pregnancy. Mol Hum Reprod 6, $19-25$.

3. Mutlu-Turkoglu U, Ademoglu E, Ibrahimoglu L, et al. (1998) Imbalance between lipid peroxidation and antioxidant status in preeclampsia. Gynecol Obstet Invest 46, 37-40.

4. Perkins AV (2006) Endogenous anti-oxidants in pregnancy and preeclampsia. Aust NZ J Obstet Gynaecol 46, 77-83.

5. Kim YJ, Hong YC, Lee KH, et al. (2005) Oxidative stress in pregnant women and birth weight reduction. Reprod Toxicol 19, 487-492.

6. Koletzko B, Agostoni C, Carlson SE, et al. (2001) Long chain polyunsaturated fatty acids (LC-PUFA) and perinatal development. Acta Paediatr 90, 460-464.

7. Willatts P \& Forsyth JS (2000) The role of long-chain polyunsaturated fatty acids in infant cognitive development. Prostaglandins Leukot Essent Fatty Acids 63, 95-100.

8. Decsi T \& Koletzko B (2005) $n$-3 Fatty acids and pregnancy outcomes. Curr Opin Clin Nutr Metab Care 8, 161-166.

9. Lakin V, Haggarty P, Abramovich DR, et al. (1998) Dietary intake and tissue concentration of fatty acids in omnivore, vegetarian and diabetic pregnancy. Prostaglandins Leukot Essent Fatty Acids 59, 209-220.

10. Makrides M, Duley L \& Olsen SF (2006) Marine oil, and other prostaglandin precursor, supplementation for pregnancy uncomplicated by pre-eclampsia or intrauterine growth restriction The Cochrane Database of Systematic Reviews 2006, issue 3, CD003402. http://www.mrw.interscience.wiley.com/ cochrane/clsysrev/articles/CD003402/frame.html

11. Olsen SF, Osterdal ML, Salvig JD, et al. (2007) Duration of pregnancy in relation to fish oil supplementation and habitual fish intake: a randomised clinical trial with fish oil. Eur J Clin Nutr 61, 976-985.

12. Gitto E, Reiter RJ, Karbownik M, et al. (2002) Causes of oxidative stress in the pre- and perinatal period. Biol Neonate 81, 146-157.

13. Herrera E (2002) Lipid metabolism in pregnancy and its consequences in the fetus and newborn. Endocrine 19, 43-55.

14. Homocysteine Lowering Trialists' Collaboration (2005) Dosedependent effects of folic acid on blood concentrations of homocysteine: a meta-analysis of the randomized trials. Am J Clin Nutr 82, 806-812.

15. Böhles H, Arndt S, Ohlenschlager U, et al. (1999) Maternal plasma homocysteine, placenta status and docosahexaenoic acid concentration in erythrocyte phospholipids of the newborn. Eur J Pediatr 158, 243-246.

16. Hayden MR \& Tyagi SC (2004) Homocysteine and reactive oxygen species in metabolic syndrome, type 2 diabetes mellitus, and atheroscleropathy: the pleiotropic effects of folate supplementation. Nutr J 3, 4.

17. Krauss-Etschmann S, Shadid R, Campoy C, et al. (2007) Effects of fish-oil and folate supplementation of pregnant women on maternal and fetal plasma concentrations of 
docosahexaenoic acid and eicosapentaenoic acid: a European randomized multicenter trial. Am J Clin Nutr 85, 1392-1400.

18. Brigelius-Flohe R, Kelly FJ, Salonen JT, et al. (2002) The European perspective on vitamin E: current knowledge and future research. Am J Clin Nutr 76, 703-716.

19. Tsuchihashi H, Kigoshi M, Iwatsuki M, et al. (1995) Action of $\beta$-carotene as an antioxidant against lipid peroxidation. Arch Biochem Biophys 323, 137-147.

20. Ames BN, Cathcart R, Schwiers E, et al. (1981) Uric acid provides an antioxidant defense in humans against oxidantand radical-caused aging and cancer: a hypothesis. Proc Natl Acad Sci U S A 78, 6858-6862.

21. Iciek M, Chwatko G, Lorenc-Koci E, et al. (2004) Plasma levels of total, free and protein bound thiols as well as sulfane sulfur in different age groups of rats. Acta Biochim Pol 51, $815-824$

22. Franke C, Verwied-Jorky S, Campoy C, et al. (2008) Dietary intake of natural sources of docosahexaenoic acid and folate in pregnant women of three European cohorts. Ann Nutr Metab 53, 167-174.

23. Knight J, Smith S, Kinder V, et al. (1988) Urinary lipoperoxides quantified by liquid chromatography, and determination of reference values for adults. Clin Chem 34, 1107-1110.

24. Hess D, Keller HE, Oberlin B, et al. (1991) Simultaneous determination of retinol, tocopherols, carotenes and lycopene in plasma by means of high-performance liquid chromatography on reversed phase. Int J Vit Nutr Res 61, 232-238.

25. Quinlan G, Evans T \& Guttridge J (2005) Oxidative damage to plasma proteins in adult respiratory distress syndrome. Free Rad Res 20, 289-298.

26. Motchnik PA, Frei B \& Ames BN (1994) Measurement of antioxidants in human blood plasma. Methods Enzymol 234, $269-279$

27. Uotila J, Tuimala R, Aarnio T, et al. (1991) Lipid peroxidation products, selenium-dependent glutathione peroxidase and vitamin E in normal pregnancy. Eur J Obstet Gynecol Reprod Biol 42, 95-100.

28. Little RE \& Gladen BC (1999) Levels of lipid peroxides in uncomplicated pregnancy: a review of the literature. Reprod Toxicol 13, 347-352.

29. Toescu V, Nuttall SL, Martin U, et al. (2002) Oxidative stress and normal pregnancy. Clin Endocrinol (Oxf) 57, 609-613.

30. Patrick TE, Hubel CA \& Roberts JM (2004) Evidence of increased oxidative stress, unexplained by lipid changes, is present in nulliparous black women from early gestation. Hypertens Pregnancy 23, 91-100.

31. Janero DR (1990) Malondialdehyde and thiobarbituric acidreactivity as diagnostic indices of lipid peroxidation and peroxidative tissue injury. Free Radic Biol Med 9, 515-540.

32. Herrera E, Ortega H, Alvino G, et al. (2004) Relationship between plasma fatty acid profile and antioxidant vitamins during normal pregnancy. Eur J Clin Nutr 58, 1231-1238.

33. Cao G \& Prior RL (1998) Comparison of different analytical methods for assessing total antioxidant capacity of human serum. Clin Chem 44, 1309-1315.

34. Van den Berg R, Haenen GRMM, van den Berg H, et al. (1999) Applicability of an improved Trolox equivalent antioxidant capacity (TEAC) assay for evaluation of antioxidant capacity measurements of mixtures. Food Chem 66, 511-517.

35. Schofield D \& Braganza JM (1996) Shortcomings of an automated assay for total antioxidant status in biological fluids. Clin Chem 42, 1712-1714.

36. Bruinse HW \& van den Berg H (1995) Changes of some vitamin levels during and after normal pregnancy. Eur $J$ Obstet Gynecol Reprod Biol 61, 31-37.

37. Cikot RJ, Steegers-Theunissen RP, Thomas CM, et al. (2001) Longitudinal vitamin and homocysteine levels in normal pregnancy. Br J Nutr 85, 49-58.

38. Clagett-Dame M \& DeLuca HF (2002) The role of vitamin A in mammalian reproduction and embryonic development. Аnnu Rev Nutr 22, 347-381.

39. Foulon T, Richard MJ, Payen N, et al. (1999) Effects of fish oil fatty acids on plasma lipids and lipoproteins and oxidantantioxidant imbalance in healthy subjects. Scand J Clin Lab Invest 59, 239-248.

40. Faure H, Preziosi P, Roussel AM, et al. (2006) Factors influencing blood concentration of retinol, $\alpha$-tocopherol, vitamin $\mathrm{C}$, and $\beta$-carotene in the French participants of the SU.VI.MAX trial. Eur J Clin Nutr 60, 706-717.

41. Chappell LC, Seed PT, Kelly FJ, et al. (2002) Vitamin C and E supplementation in women at risk of preeclampsia is associated with changes in indices of oxidative stress and placental function. Am J Obstet Gynecol 187, 777-784.

42. Powers RW, Bodnar LM, Ness RB, et al. (2006) Uric acid concentrations in early pregnancy among preeclamptic women with gestational hyperuricemia at delivery. Am J Obstet Gynecol 194, 160.

43. Becker BF (1993) Towards the physiological function of uric acid. Free Radic Biol Med 14, 615-631.

44. Glantzounis GK, Tsimoyiannis EC, Kappas AM, et al. (2005) Uric acid and oxidative stress. Curr Pharm Des 11, 4145-4151.

45. Sanchez-Lozada LG, Nakagawa T, Kang DH, et al. (2006) Hormonal and cytokine effects of uric acid. Curr Opin Nephrol Hypertens 15, 30-33.

46. Lain KY, Markovic N, Ness RB, et al. (2005) Effect of smoking on uric acid and other metabolic markers throughout normal pregnancy. J Clin Endocrinol Metab 90, 5743-5746.

47. Wisdom SJ, Wilson R, Mckillop JH, et al. (1991) Antioxidant systems in normal pregnancy and in pregnancy hypertension. Am J Obstet Gynecol 165, 1701-1704.

48. Raijmakers MT, Roes EM, Steegers EA, et al. (2001) Umbilical cord and maternal plasma thiol concentrations in normal pregnancy. Clin Chem 47, 749-751.

49. Myatt L \& Cui X (2004) Oxidative stress in the placenta. Histochem Cell Biol 122, 369-382.

50. Walsh SW (1998) Maternal-placental interactions of oxidative stress and antioxidants in preeclampsia. Semin Reprod Endocrinol 16, 93-104.

51. Koletzko B, Cetin I \& Brenna JT (2007) Dietary fat intakes for pregnant and lactating women. Br J Nutr 98, 873-877.

52. Simopoulos AP, Leaf A \& Salem N Jr (2000) Workshop statement on the essentiality of and recommended dietary intakes for omega-6 and omega-3 fatty acids. Prostaglandins Leukot Essent Fatty Acids 63, 109-121. 